Journal of Environmental
ASSN: $2525-815 \mathrm{X}$

\title{
Análise temporal da recuperação de área de mineração em Paragominas pela técnica de regeneração natural por meio de índices de vegetação
}

\section{Temporal analysis of mining area recovery in Paragominas by natural regeneration technique through vegetation indices}

Jessica dos Santos Cugula ${ }^{a^{*}}$, Raíssa André de Araujo ${ }^{\mathrm{b}}$, Larissa Sampaio Freire ${ }^{\mathrm{a}}$, Jonilton Pantoja Paschoal $^{\mathrm{b}}$, Ana Karla dos Santos Pontes ${ }^{\mathrm{b}}$, Cláudia do Rosário Vaz Morgado ${ }^{\mathrm{c}}$, Elisa Maria Mano Esteves $^{\mathrm{c}}$

${ }^{a}$ Universidade Federal do Rio de Janeiro-UFRJ, Departamento de Recursos Hídricos. Av. Athos da Silveira Ramos, n. 149, Bloco A, Cidade Universitária, Rio de Janeiro-RJ, Brasil. CEP: 21941-909. E-mail: dossantosjessica10@poli.ufrj.br (Autor correspondente), 1arissafreire31@poli.ufrj.br.

${ }^{\mathrm{b}}$ UFRJ, Programa de Planejamento Energético (PPE), COPPE. Rua Moniz Aragão No 360, Bloco 1, Ilha do Fundão, Cidade Universitária, Rio de Janeiro-RJ, Brasil. CEP: 21941-594. E-mail: raissaa.araujo@ poli.ufrj.br.

${ }^{\mathrm{c}}$ Mineração Paragominas S. A. Rua Estrada da Mineração, s/n, km 30 a partir da rodovia BR 010, Platô Miltônia 3, Paragominas-PA. CEP: 68.625-200. E-mail: jonilton.paschioal@hydro.com, ana.pontes@hydro.com.

d UFRJ, Programa de Engenharia Ambiental-PEA. E-mail: cmorgado@ poli.ufrj.br, elisa.esteves@ poli.ufrj.br.

\section{A R T I C L E I N F O}

Recebido 30 Jun 2020

Aceito 25 Ago 2021

Publicado 25 Nov 2021

\begin{abstract}
A B S T R A C T
Bauxite extraction is one of the most important segments of the mining industry in Brazil. Despite this, its exploitation occurs mainly in the country's North region, where the Amazon Forest is located. Deforestation for an extractive practice can lead to irreversible environmental damage. Using the natural regeneration technique, the study's objective is a temporal analysis of vegetation recovery in an area impacted by bauxite mining in Pará, Brazil. The analysis was performed using Landsat satellite images to calculate the Normalized Difference Vegetation Index - NDVI, the Soil Adjusted Vegetation Index - SAVI, and the Enhanced Vegetation Index - EVI, using numerical and visual evaluations. The image's dates are from the pre-impact period (1984-2006), during mining activity (2007-2009), and after the application of the natural regeneration technique (2010-2019). The natural regeneration technique proved to be efficient in vegetation recovery. After the technique's application, the recovery from the numerical analysis corresponds to an increase in the absolute values of $110 \%$ for NDVI and SAVI and $120 \%$ for EVI. A visual assessment detected heterogeneity in terms of recovery, which allows the definition of areas in need of future interventions. Ten years after applying the technique, the region is in the stage of development close to the advanced stage of recovery. Thus, recovery techniques need to be strategically chosen and followed for a long period.
\end{abstract}

Keywords: Area recovery, vegetation indices, mining area, remote sensing, NDVI, SAVI, EVI.

\section{R E S U M O}

O extrativismo de bauxita é um dos mais importantes segmentos da indústria mineradora do Brasil. Apesar disso, sua exploração ocorre principalmente na região norte do país, onde encontra-se a Floresta Amazônica. O desmatamento para a prática extrativista pode levar a danos ambientais irreversíveis. O objetivo do estudo é a análise temporal da recuperação vegetal em uma área impactada pela mineração de bauxita no Pará, Brasil, por meio da técnica de regeneração natural. A análise foi realizada utilizando imagens de satélite Landsat para calcular o Índice de Vegetação por Diferença Normalizada - NDVI, o Índice de Vegetação Ajustado ao Solo - SAVI e o Índice de Vegetação Melhorado - EVI, por meio de análises numéricas e visuais. As datas das imagens cobrem o período pré impacto (1984-2006), durante a 
mineração (2007-2009) e após a aplicação da regeneração natural (2010-2019). A técnica de regeneração natural, mostrou-se eficiente para a melhoria da área. Pela análise numérica, a recuperação, após a aplicação da técnica, corresponde a um crescimento dos valores absolutos de $110 \%$ para o NDVI e SAVI e $120 \%$ para o EVI. $\mathrm{Na}$ avaliação visual detectou-se heterogeneidade quanto à recuperação, o que possibilita a definição de regiões passíveis de futuras intervenções. Verifica-se que após dez anos da aplicação da técnica, a região encontra-se em estágio de desenvolvimento próximo ao estágio avançado de recuperação. Assim, as técnicas de recuperação precisam ser estrategicamente escolhidas e acompanhadas a longo prazo.

Palavras-Chave: Recuperação da vegetação, área de mineração, sensoriamento remoto, NDVI, SAVI, EVI.

\section{Introdução}

A mineração é uma das atividades produtivas mais antigas da humanidade, incluindo a extração e processamento de minerais, em seu estado natural, presentes em rochas ou no solo, e têm um viés fundamentalmente econômico (ANM, 2020). Essa atividade fornece a geração de uma ampla variedade de produtos que são apreciados pela humanidade. Além disso, a mineração se apresenta como uma atividade bastante complexa que envolve investimentos, planejamento, extração de recursos naturais finitos, interação com órgãos reguladores, comunidade e meio ambiente (ABAL, 2017).

A indústria de extração mineral possui grande importância no cenário brasileiro, visto que alavanca o setor industrial ao fornecer matériaprima para outras indústrias. Além disso, segundo o Instituto Brasileiro de Mineração (IBRAM, 2018), a mineração representa $1,4 \%$ de todo o PIB brasileiro, empregando 180 mil trabalhadores. Em 2019, o Brasil exportou mais de 363 milhões de toneladas de bens minerais, o que representa $53,6 \%$ do peso total exportado, e gerou US \$ FOB 25,8 bilhões, equivalentes a $11,5 \%$ do total exportado, $1,6 \%$ a mais do que em 2018 (Ministério da Economia, 2020). Além da geração de empregos diretos, a atividade pode trazer prosperidade para regiões pouco desenvolvidas (Worlanyo \& Jiangfeng, 2021), através do aumento de empregos indiretos, da arrecadação da região e obras de infraestrutura.

A bauxita é uma rocha sedimentar de cor avermelhada, rica em alumínio. Este, por sua vez, é o terceiro elemento mais abundante na crosta terrestre, depois do oxigênio e do silício. $\mathrm{O}$ alumínio é um dos minerais que mais agrega valor ao seu setor, pois para cada real obtido na extração desse minério são gerados $R \$ 16,00$ nas etapas de produção. As reservas nacionais de bauxita contêm mais de $40 \%$ de óxido de alumínio utilizável e estão entre as maiores do mundo. A bauxita é o recurso natural que ocupa o terceiro lugar em termos de volume produzido no Brasil, com cerca de 37 milhões de toneladas por ano, após agregados para a construção civil e minério de ferro (ABAL, 2017), e a produção brasileira de bauxita ocupou o quarto lugar, em 2018, depois da Austrália, China e Guiné (USGS, 2019). Sua industrialização gera impostos, empregos e agrega valor à cadeia produtiva nacional.

No Brasil, a presença de empresas transnacionais de minério na região Norte, onde está localizado o bioma Amazônico, tornou-a um destaque econômico, principalmente nos estados do Pará e Amapá. O estado do Pará é o segundo maior produtor mineral nacional, depois de Minas Gerais, que desenvolve a atividade desde o período colonial. No Pará, a reserva de bauxita ocupa a segunda maior reserva de minério de metal, atrás apenas do ferro. Além disso, neste estado, estão localizadas as três das maiores operações de mineração aberta de bauxita do país, responsáveis por processar cerca de 93,4\% do total nacional de bauxita e por produzir 90\% do alumínio em 2016 (DNPM, 2017; DNPM, 2018).

A mineração de bauxita demanda grandes áreas e, diferentemente de outros minérios, é realizada ao ar livre, segundo o método de mineração em tiras, no qual grandes tiras de terra são extraídas e recuperadas em sequência. $\mathrm{O}$ processo envolve desmatamento, decapagem, escavação do minério, transporte para o triturador, descarte de material estéril, desmontagem do minério, carregamento e transporte para a usina de beneficiamento e reabilitação da área arada, envolvendo o descarte da cobertura vegetal e da camada de solo removido anteriormente para recuperar o solo. Essa recuperação também envolve a reconstituição de uma floresta secundária promovida pelo replantio de espécies endêmicas. $\mathrm{O}$ material de decapagem também é usado em obras de infraestrutura civil, construção de diques de rejeitos e terraplenagem na área da planta de beneficiamento. No processamento, a bauxita tem sua qualidade aprimorada e seu volume reduzido para facilitar o manuseio e os custos com transporte (Sampaio, Andrade \& Dutra, 2005; ABAL, 2017).

Diversos impactos ambientais e socioculturais podem ser obtidos com a mineração 
(Sampaio, Andrade \& Dutra, 2005; ABAL, 2017). De maneira geral, esta atividade pode levar a perda de biodiversidade (Wanderley, 2008), e perda de propriedades do solo, como a capacidade de reter e infiltrar a água, favorecendo a erosão do solo. Também é relevante destacar que a atividade gera mudanças na topografia e na paisagem, podendo levar à contaminação da água devido aos resíduos de mineração, poluição do ar e sonora (Bunker, 1985; Trindade, 2019).

Visando minimizar os impactos ambientais causados pela mineração de bauxita, ocorre paralelamente ao processo de mineração um processo de recuperação de áreas degradadas, que se baseia em medidas de revegetação para estabelecer a sucessão natural nessas áreas. Estas devem levar em consideração as características ambientais e usos futuros da área, assim como definido pela legislação, que estabelece que $80 \%$ da propriedade localizada em áreas rurais na Amazônia seja indicada para a Reserva Legal (Brasil, 2012). Tais medidas são de grande importância num contexto de degradação ambiental, devido ao histórico de ocupação e uso do solo em regiões de florestas na Amazônia, no sentido de buscar salvaguardar e preservar a vegetação nativa (Duarte et al., 2020). Dentre algumas das principais técnicas de recuperação de áreas degradadas estão o plantio de mudas, a semeadura direta, a indução da regeneração natural e o depósito de serapilheira e solo superficial.

A regeneração natural se apresenta como uma técnica responsável pelo processo sucessional de um ecossistema, além de ser bastante econômica e demandar menos trabalho e insumos (Schorn et al., 2010). Consiste no retorno de resíduos vegetais e solo superficial anteriormente removidos na mineração para serem realizados tratamentos silviculturais, por meio do plantio de espécies nativas (Martins, Ferreira \& Oliveira, 2018).

A regeneração natural é mais sensível em comparação com outras técnicas, porque possui vários fatores limitantes, bióticos e abióticos. Seu sucesso dependerá de operações silviculturais que garantam uma melhor produção de sementes; um bom ambiente para germinação e estabelecimento das espécies; condições climáticas do local para promover o estabelecimento das espécies pioneiras que iniciarão o processo sucessional (Soares, 2012); bem como o grau de degradação da área, porque em áreas muito degradadas o solo é pobre em nutrientes, portanto esse método não será muito eficiente no processo de recuperação dessas áreas (Almeida, 2002). Apesar disso, a técnica de regeneração natural apresenta-se como a técnica mais coerente em termos de alcançar uma boa reabilitação e restauração da área, porque mais do que alcançar proximidade com a condição anterior, essa técnica por sucessão natural garante condições de estabilidade no ambiente (Mariath \& Santos, 2006).

Além da regeneração natural, existem outras técnicas, como o plantio tradicional e nucleação, por exemplo. A técnica do plantio tradicional é uma das mais utilizadas no processo de restauração de áreas degradadas pela mineração e consiste no plantio de mudas de espécies arbóreas nativas. No entanto, esse método é um tanto oneroso, devido à mortalidade de mudas em áreas minadas e é um processo que realiza a recuperação através de florestas artificiais, causando estagnação sucessional e redução da diversidade (Mariath \& Santos, 2006). Comparado à técnica tradicional de plantio, a regeneração natural apresenta maior volume de deposição de serapilheira, maior concentração e teor de nutrientes, sendo mais eficiente na restauração de áreas degradadas pela mineração de bauxita (Martins, Ferreira \& Oliveira, 2018). A nucleação, por outro lado, permite que espécies pioneiras melhorem as condições ambientais de um ecossistema degradado, facilitando o estabelecimento de espécies subsequentes, por meio da criação de núcleos naturais e atrativos que facilitam a reintrodução e o contato de espécies que aumentarão o processo de sucessão e garantirão a biodiversidade. Em relação à regeneração natural, a nucleação é uma técnica mais recente, porém mais onerosa, devido ao seu sucesso ser mais bem garantido com a implementação conjunta de várias técnicas de nucleação, além de poder causar degradação devido ao uso de espécies exóticas diante da dificuldade de obter, em um estágio inicial, espécies nativas. Além disso, seu sucesso é limitado em termos de proximidade às áreas mais conservadas, uma vez que estas suprirão a área degradada (Reis et al., 2003; Mariath \& Santos, 2006; Marcuzzo et al., 2013).

Para acessar áreas distantes sem a necessidade de coletar dados diretamente no local da análise é utilizado o sensoriamento remoto, que identifica objetos indiretamente usando campos de força naturais ou artificiais, com o objetivo de analisar a cobertura vegetal de áreas degradadas (Qi, Wang \& Zhang, 2013; Konecny, 2014; Bacalhau, Ribeiro Neto \& Oliveira, 2017). É amplamente utilizado no monitoramento e detecção de mudanças sob cobertura vegetal em áreas de exploração mineral (Sirtoli, 1998). Visando auxiliar no monitoramento da dinâmica da cobertura vegetal, existem os índices de vegetação, que são calculados a partir das combinações de diferentes bandas de imagens de satélite, obtidas através do sensoriamento remoto, que servem para 
destacar as características da vegetação (Huete, Justice \& Van Leeuwen, 1999; Gao et al., 2000).

Diferentes estudos aplicaram a técnica de regeneração natural para a recuperação de áreas degradadas. Parrotta \& Knowles (2001), Jesus et al. (2016) e Martins (2020) utilizaram conceitos ecológicos e de diversidade de espécies na comparação de diferentes técnicas de recuperação vegetal em área de mineração. Considerando o sensoriamento remoto, Araujo et al. (2020) realizaram comparação entre técnicas de plantio e Oliveira et al. (2017) apresentaram o monitoramento da recuperação vegetal de um incêndio florestal.

Em 2009, iniciou-se a aplicação da técnica de regeneração natural em uma área do município de Paragominas, PA, Brasil, impactada pela mineração de bauxita entre 2007 e 2009. Assim, diferentemente dos outros estudos realizados, esta investigação consiste na análise temporal, com curto intervalo de tempo entre as imagens, da recuperação vegetal desta região após a atividade mineradora, comparando-a não somente com o período impactado, como também com o período anterior à atividade.

\section{Material e Métodos}

O município de Paragominas está localizado no bioma Amazônia e possui clima do tipo equatorial úmido. A temperatura média fica em torno de $25^{\circ} \mathrm{C}$, com duas estações bem definidas: uma relativamente seca (entre junho e dezembro), e outra com altas taxas de precipitação (entre janeiro e maio) (Carvalho, Costa \& Oliveira, 2005). A região possui uma superfície tabular achatada e bastante recortada (Rodrigues et al., 2003; Pereira \& Souza, 2019), com solo de latossolo predominante (Alves et al., 2021).

Seu histórico contempla alterações na paisagem da vegetação nativa devido aos diversos usos da terra ocorridos ao longo do tempo. Antes da chegada da mineração, a região contava com o impacto dos usos anteriores da terra devido às elevadas taxas de desmatamento por conta da exploração madeireira, abertura de vastos campos para pasto, e ao agronegócio extensivo, sendo a soja e a pecuária os principais responsáveis pelo incremento deste último fator (Sousa et al., 2017).

$\mathrm{O}$ presente estudo é baseado em três períodos temporais: antes da atividade mineradora (1984-2006), durante a atividade mineradora (2007-2009), e após a aplicação da técnica de regeneração natural (2010-2019).

Entre os anos 1984 e 2006, a atividade mineradora não tinha sido estabelecida na região de estudo e a área era coberta por uma floresta secundária. O município de Paragominas possuía grande parte de sua área desmatada devido às atividades de exploração de madeira (Francez et al., 2009) e agropecuária (Thompson \& Lima, 2017).

No período de 2007 até 2009, ocorreu o desmatamento para a exploração da bauxita, de forma gradual. Em 2009, após finalizada a atividade, iniciou-se a aplicação da técnica de regeneração natural, no entanto, não se sabe sua data específica e a duração. Devido a esta limitação, considera-se o início do período de recuperação no ano de 2010. Durante este período é esperado que o uso do solo evolua de solo exposto até alcançar um estágio avançado de recuperação. O tempo necessário para melhoria da área depende de fatores como região, condições climáticas, entre outros fatores, sendo um processo que precisa ser monitorado a longo prazo (Almeida, 2002; Mariath \& Santos, 2006; Soares, 2012; Silva et al., 2016).

A área de estudo foi delimitada pela equipe de Meio Ambiente que atua na Mineração Paragominas (Hydro Paragominas), disponibilizada por meio de um shapefile, arquivo vetorial georreferenciado, com a delimitação das áreas replantadas em $2009\left(210.419 \mathrm{~m}^{2}\right)$. As coordenadas do centroide da área de estudo são $3^{\circ} 15^{\prime} 39,83^{\prime \prime}$ 'S e $47^{\circ} 42^{\prime} 54,90$ 'O.

Um total de 71 imagens dos satélites Landsat 5,7 e 8 foram utilizadas nesta pesquisa, cobrindo temporalmente os períodos entre os anos 1984 e 2019. A escolha do satélite foi baseada em características de temporalidade, resolução e disponibilidade gratuita. As imagens foram obtidas do Serviço Geológico dos Estados Unidos da América (United States Geological Survey USGS), com órbita/ponto igual a 223/062, atmosfericamente corrigidas com o método padrão do USGS (6s) e convertidas para reflectância. Das imagens que se encontravam disponíveis, foram selecionadas as datas que apresentavam pouca ou nenhuma nuvem na área de estudo (Tabela 1 Material Suplementar). As imagens são compostas por bandas, obtidas por diferentes sensores e que possuem dados de diferentes faixas do espectro eletromagnético. Os Landsats 5 e 7 apresentam 7 diferentes bandas e o Landsat 8 apresenta 11 diferentes bandas do espectro eletromagnético (USGS, 2020). Todas as imagens foram baixadas no formato geotiff e processadas no ArcGIS 10.5 (ESRI).

As bandas das imagens do satélite Landsat foram combinadas de forma a possibilitar o cálculo para três índices de vegetação distintos: NDVI (Índice de Vegetação por Diferença Normalizada Normalized Difference Vegetation Index), SAVI (Índice de Vegetação Ajustado ao Solo - Soil Adjusted Vegetation Index) e EVI (Índice de 
Vegetação Melhorado - Enhanced Vegetation Index). A aplicação destes índices permite resultados comparativos, o que adere ao grau de confiabilidade do resultado, além de definir os melhores índices para as condições de mudança de estágio de desenvolvimento e climatológicas.

O NDVI foi selecionado por ser o mais utilizado em pesquisas acadêmicas, assim como o EVI (Xu et al., 2018). Além dessas, é aplicado o SAVI, o qual, embora não seja um dos mais utilizados, está presente em vários artigos sobre o assunto, como o estudo de Ma et al. (2017), que procuraram monitorar a poeira de folhas em uma área de mineração, e Shank (2008), que mapeou a densidade da vegetação em uma superfície recuperada de área de mineração.

O NDVI é utilizado devido à sua forte correlação com a fotossíntese e produção primária de vegetação, sendo um indicador eficiente da proporção e condição da vegetação (Wilson \& Norman, 2018). O índice NDVI é calculado aplicando a Equação 1 (Rouse et al., 1974).

$$
N D V I=\frac{\rho_{I V P}-\rho_{V}}{\rho_{I V P}+\rho_{V}}
$$

onde, $\rho I V P=$ reflectância do infravermelho próximo (banda 4 do Landsat 5 e 7; banda 5 do Landsat 8 ); $\rho \mathrm{V}=$ reflectância do vermelho (banda 3 do Landsat 5 e 7; banda 4 do Landsat 8).

O SAVI é um refinamento e calibração do NDVI a fim de minimizar os efeitos de superfície de áreas não completamente cobertas por vegetação, principalmente na fase inicial de recuperação (Huete, 1988; Boratto \& Gomide, 2013). Esta modificação ocorre através do uso de um fator de ajuste que procura minimizar os efeitos da reflexão do solo, que pode ser adaptado de acordo com a vegetação estudada, embora por simplificação tenha sido adotado o 0,5 , pois este valor reduz o ruído em todos os tipos de densidade de vegetação (Gilabert et al., 2002; Eastman, 2006; Huete, 1988). O índice SAVI é calculado aplicando a Equação 2.

$S A V I=(L+1) \frac{\rho_{I V P}-\rho_{V}}{L+\rho_{I V P}+\rho_{V}}$

onde $\rho \mathrm{IVP}=$ reflectância do infravermelho próximo (banda 4 do Landsat 5 e 7; banda 5 do Landsat 8); $\rho \mathrm{V}=$ reflectância do vermelho (banda 3 do Landsat 5 e 7; banda 4 do Landsat 8); $\mathrm{L}=$ fator de ajuste $(0,5)$.

O EVI é uma melhoria do índice NDVI, foi criado a partir do SAVI e o Índice de vegetação resistente à atmosfera - Atmospherically resistant vegetation index (ARVI), pois foi reduzido o efeito de solo de fundo e os ruídos atmosféricos, além do problema de saturação. Isso ocorreu devido à adição do espectro azul e algumas constantes na fórmula original, aumentando a sensibilidade à discriminação de variações estruturais em áreas com vegetação muito densa (Huete, Justice, \& Van Leeuwen, 1999; Huete et al. 2002). A Equação 3 é utilizada para calcular os valores de EVI.

$$
E V I=2,5 \frac{\rho_{I V P}-\rho_{V}}{\rho_{I V P}+6 \rho_{V}-7,5 \rho_{A}+1}
$$

onde, $\rho \mathrm{IVP}=$ reflectância do infravermelho próximo (banda 4 do Landsat 5 e 7; banda 5 do Landsat 8$) ; \rho \mathrm{V}=$ reflectância do vermelho (banda 3 do Landsat 5 e 7; banda 4 do Landsat 8); $\rho \mathrm{A}=$ reflectância do azul (banda 1 do Landsat 5 e 7; banda 2 do Landsat 8); 6 = coeficiente de correção atmosférica para o vermelho; 7,5 = coeficiente de correção atmosférica para o azul; 1 = fator de correção da interferência do solo; 2,5 = fator de ganho.

Por meio do software ArcGIS 10.5 (ESRI) foi utilizada a ferramenta Raster Calculator para a aplicação das equações dos índices de vegetação utilizando as bandas do satélite Landsat referentes aos espectros de cada variável da equação. O resultado é um raster em que cada pixel possui um valor distinto, resultado das equações para cada índice NDVI (Equação 1), SAVI (Equação 2) e EVI (Equação 3). A ferramenta "Zona Estatística como Tabela" é utilizada para calcular a média de valores para toda a área de estudo, por meio da intersecção entre o shapefile da área de estudo e o raster com os índices calculados.

Os valores dos índices variam de acordo com o uso do solo e o estágio de desenvolvimento da vegetação na área. Para o NDVI (Equação 1) e EVI (Equação 3), os valores variam de $-1,0$ até 1,0 , para o SAVI (Equação 2) foi de -1,5 até 1,5. Os valores negativos e muito próximos de zero são de pixels que representam corpos hídricos, logo acima de zero é para solo exposto e a partir desse ponto os valores crescem de acordo com o desenvolvimento da vegetação.

As diferentes áreas ao redor do mundo possuem faixas de valores características para os estágios de desenvolvimento vegetal, devido à variação da flora, assim como das condições climáticas. Para uma análise mais real os valores foram alocados em faixas relacionadas às características dos arredores da mineradora. Adaptado de Chagas et al. (2008) e Laurentino et al. (2011), a classificação aplicada para faixas de valores dividiram-se em: (a) Solo Exposto, ausência de vegetação, indica uma área utilizada para a operação de mineração ou explorada recentemente; (b) Campo Aberto, presença de 
gramínea ou vegetação baixa, indicando estágio inicial de crescimento vegetal; (c) Vegetação Esparsa, áreas de vegetação baixa ou média com presença de pequenas árvores espaçadas; (d) Vegetação Transicional, vegetação em estágio intermediário de desenvolvimento com áreas de vegetação em estágio avançado; (e) Vegetação Densa, área de vegetação desenvolvida que se assemelha às características da floresta presente no período de pré-mineração, com diferenças de altura causadas pela presença de estágios sucessionais distintos.

A área de cada tipo de vegetação foi identificada por meio do método de falsa-cor onde uma combinação de bandas do satélite Landsat é utilizada para ressaltar a vegetação, através de uma análise visual considerando os aspectos de cor, formato e textura da imagem (Esteves et al., 2016), além de conhecimentos prévios da área. A delimitação das regiões ocorreu utilizando polígonos de área entre 10.000 e $20.000 \mathrm{~m}^{2}$, escolhidos por apresentarem características homogêneas, dos tipos de vegetação selecionados, em toda a sua extensão.

As faixas estabelecidas para cada classificação foram encontradas por meio dos valores dominantes nos polígonos gerados, verificados por meio de histogramas, gráficos que apresentavam a divisão dos valores encontrados na área, para cada índice, selecionando as três faixas com maior número de elementos, ou seja, maior quantidade de pixels. $\mathrm{O}$ menor valor destas três faixas foi definido como valor mínimo da classificação calculada, assim como o maior valor como o valor máximo da mesma. Para melhor precisão dos resultados, foram utilizadas as imagens com valores extremos na análise, e confirmados utilizando imagens com valores intermediários. Os diferentes tipos de vegetação tinham faixas que se sobrepunham em seus valores extremos, de forma que para fazer uma série de intervalos contínuos o menor valor de uma faixa tornou-se o limitante da faixa anterior. Esta análise é útil na comparação dos diferentes valores dos índices que representam o mesmo estágio da vegetação, sabendo que todos eles apresentam faixas e respostas diferentes para as regiões.

A Tabela 1 mostra as faixas de valores para os três índices para os estágios de desenvolvimento vegetal mais presentes na área.

Tabela 1. Faixa do Índice de Vegetação por Diferença Normalizada (NDVI), Índice de Vegetação Ajustado ao Solo (SAVI) e do Índice de Vegetação Melhorado (EVI) para diferentes estágios de desenvolvimento da vegetação. Min = limite inferior; Max = limite superior. Fonte: Cugula et al. (2021).

\begin{tabular}{lcccccc}
\hline \multirow{2}{*}{ Estágio } & \multicolumn{2}{c}{ NDVI } & \multicolumn{2}{c}{ SAVI } & \multicolumn{2}{c}{ EVI } \\
\cline { 2 - 7 } & Min & Max & Min & Max & Min & Max \\
\hline Solo Exposto & 0,06 & 0,09 & 0,05 & 0,08 & 0,03 & 0,06 \\
Campo Aberto & 0,09 & 0,29 & 0,08 & 0,21 & 0,06 & 0,17 \\
Vegetação Esparsa & 0,29 & 0,54 & 0,21 & 0,39 & 0,17 & 0,38 \\
Vegetação Transicional & 0,54 & 0,75 & 0,39 & 0,45 & 0,38 & 0,48 \\
Vegetação Densa & 0,75 & 0,92 & 0,45 & 0,60 & 0,48 & 0,65 \\
\hline
\end{tabular}

Trabalhando com um grande banco de informações, é necessária a identificação e retirada de valores atípicos para que a análise não seja prejudicada (Pinheiro et al., 2012). Para essa identificação foi escolhido o método de cercas inferior e superior, utilizando o parâmetro estatístico média, onde a partir destas identificamse os outliers, ou seja, valores discrepantes na amostra. O Q1 é o primeiro quartil e demonstra a posição onde se encontram os $25 \%$ dos valores mais baixos da amostra (Equação 4). O Q2 é o segundo quartil e a mediana, onde estão $50 \%$ dos valores (Equação 5). O Q3 é o terceiro quartil e apresenta a posição com $75 \%$ dos valores mais baixos (Equação 6). A diferença interquartil (DIQ) é a diferença entre Q3 e Q2 (Montgomery \&
Runger, 2010) (Equação 7). A combinação dos parâmetros calculados anteriormente é utilizada para o cálculo da cerca superior (Equação 8), onde valores acima desta são removidos da amostra, e da cerca inferior (Equação 9), onde são eliminados valores menores em relação a ela. O gráfico do boxplot, gerado no software Excel (Microsoft) foi escolhido para apresentar esta parte e sua explicação está presente na Figura 1. Isto foi feito para cada índice de vegetação, para antes da implementação da técnica de recuperação.

$$
\begin{aligned}
& Q 1=X\left(\frac{n+3}{4}\right) \\
& Q 2=X\left(\frac{n+1}{2}\right)
\end{aligned}
$$



$Q 3=X\left(\frac{3 n+1}{4}\right)$
Cerca superior $=Q 3+1,5 D I Q$
(Eq. 9)
$D I Q=Q 3-Q 1$
onde: $\mathrm{n}=$ número de elementos da amostra (51); $\mathrm{X}$

Cerca inferior $=Q 1-1,5 D I Q$
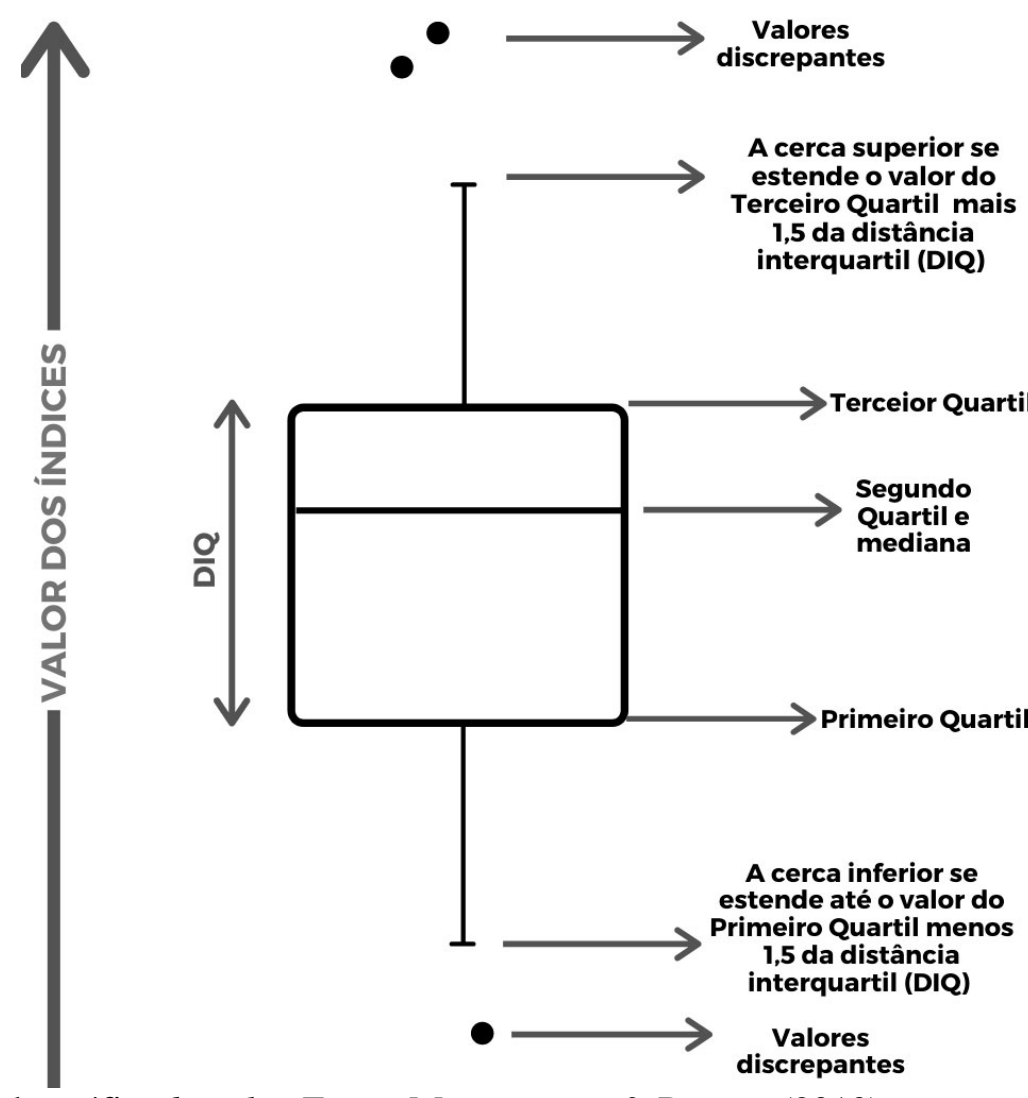

Figura 1. Descrição do gráfico boxplot. Fonte: Montgomery \& Runger (2010).

Após a retirada dos valores discrepantes, calculou-se o maior valor (MAX), menor valor (MIN) e desvio padrão (DP) e o coeficiente de variação $(\mathrm{CV})$ para cada período. Esse coeficiente é utilizado para a análise da dispersão dos dados, aplicando a classificação de Gomes (1985), com as classes: baixa $(\mathrm{CV}<0,1)$, média $(0,1<\mathrm{CV}<0,2)$, alta $(0,2<\mathrm{CV}<0,3)$ e muito alta $(\mathrm{CV}>0,3)$.

As imagens proporcionam valores absolutos diários para os três índices, que são representativas para dados mensais e anuais. As imagens serão trabalhadas de forma numérica e visual. A análise numérica utiliza a média de valores distintos de cada pixel. Por meio da análise visual é possível abranger os diferentes valores presentes em cada pixel, sem a necessidade da simplificação da média, permitindo verificar como os valores são distribuídos espacialmente na área. Além de valores absolutos pode-se trabalhar com a classificação dos diferentes estágios de vegetação, tanto para a média como para os valores em nível de pixel.

\section{Resultados e Discussão}

Com o intuito de observar a variação, centralidade e dispersão dos dados, além de possibilitar a exclusão das medidas discrepantes, os valores foram organizados em boxplots. $\mathrm{O}$ diagrama foi aplicado apenas para o período anterior a atividade mineradora em questão, dado que durante a atividade mineradora e após ela os valores estavam muito dispersos por conta dos diferentes usos na área com o passar do tempo, não podendo ser esperado nenhuma regularidade.

Os boxplots para o NDVI, SAVI e EVI são apresentados na Figura 2. Para o NDVI (Figura 2A) houve seis imagens com valores menores do que a cerca inferior $(0,594)$ que foram descartados, das quais cinco apresentaram presença de nuvens na área de estudo. Para o SAVI (Figura 2B) e EVI (Figura 2C), respectivamente, todos os valores estão dentro dos limites, não havendo valores discrepantes. As medianas dos índices são 0,819 (NDVI), 0,465 (SAVI) e 0,484 (EVI). Dessa forma, 
a maioria dos valores desse período estão

classificados como vegetação densa.

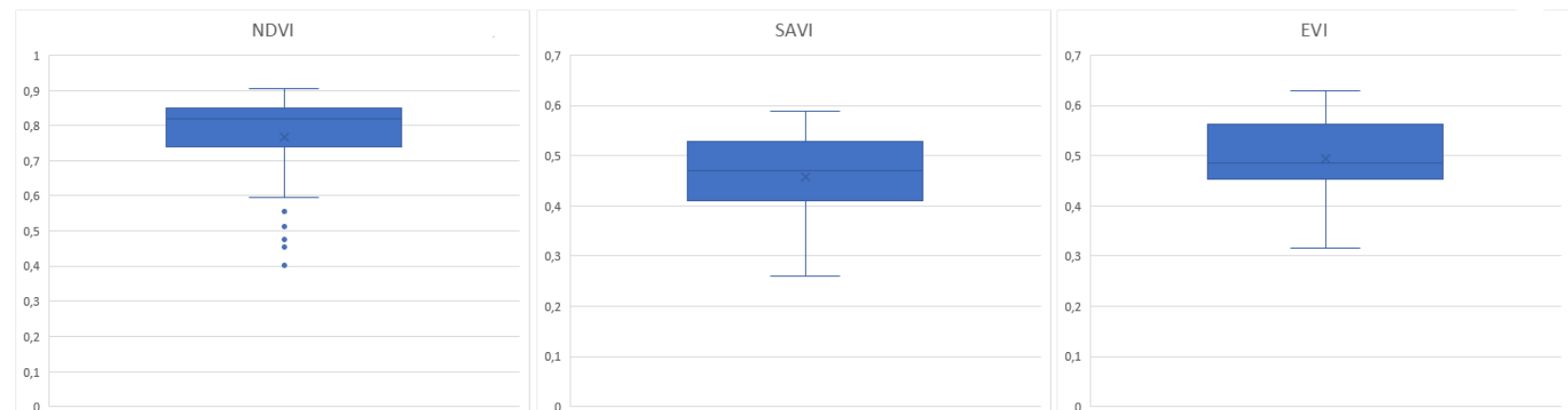

Figura 2. Boxplot para o Índice de Vegetação por Diferença Normalizada (NDVI), Índice de Vegetação Ajustado ao Solo (SAVI) e o Índice de Vegetação Melhorado (EVI), para os valores de 1984 até 2006. Fonte: Cugula et al. (2021).

A Tabela 2 mostra os valores dos parâmetros estatísticos média, valor máximo, valor mínimo, desvio padrão e coeficiente de variação, para os três índices utilizados, separados temporalmente em antes, durante e após a mineração. Dessa forma, é possível comparar as características de cada período. Estes dados foram obtidos a partir de valores absolutos diários dos três períodos analisados (Tabela 2).

Tabela 2. Parâmetros estatísticos para o valor médio das imagens (nos períodos especificados), para o Índice de Vegetação por Diferença Normalizada (NDVI), Índice de Vegetação Ajustado ao Solo (SAVI) e o Índice de Vegetação Melhorado (EVI). Max = Valor máximo; Min = Valor mínimo; $\mathrm{DP}=$ Desvio-Padrão; $\mathrm{CV}=$ Coeficiente de Variação. Fonte: Cugula et al. (2021).

\begin{tabular}{|c|c|c|c|c|c|c|c|c|c|}
\hline & \multicolumn{3}{|c|}{$\begin{array}{l}\text { Antes da mineração } \\
(1984-2006)\end{array}$} & \multicolumn{3}{|c|}{$\begin{array}{c}\text { Durante a mineração } \\
(2007-2009)\end{array}$} & \multicolumn{3}{|c|}{$\begin{array}{c}\text { Depois da mineração } \\
(2010-2019)\end{array}$} \\
\hline & NDVI & SAVI & EVI & NDVI & SAVI & EVI & NDVI & SAVI & EVI \\
\hline Média & 0,805 & 0,458 & 0,495 & 0,315 & 0,184 & 0,179 & 0,522 & 0,344 & 0,339 \\
\hline Max & 0,906 & 0,589 & 0,630 & 0,537 & 0,343 & 0,353 & 0,741 & 0,493 & 0,512 \\
\hline Min & 0,595 & 0,261 & 0,315 & 0,203 & 0,090 & 0,076 & 0,298 & 0,196 & 0,185 \\
\hline DP & 0,074 & 0,082 & 0,076 & 0,128 & 0,099 & 0,111 & 0,166 & 0,107 & 0,116 \\
\hline $\mathrm{CV}$ & 0,092 & 0,178 & 0,153 & 0,407 & 0,538 & 0,620 & 0,318 & 0,312 & 0,342 \\
\hline
\end{tabular}

Analisando os índices obtidos na Tabela 2, a partir das faixas de estágios de desenvolvimento obtidos na Tabela 1, observa-se que os valores máximos e médios estão todos na faixa de vegetação densa. Para o NDVI, o valor mínimo está na faixa de vegetação de transição, os índices EVI e SAVI estão na faixa de vegetação esparsa, por conta da presença de clareiras na área. Quanto às medidas de dispersão, o CV foi classificado como "Baixo" (CV $<0,1)$ para o NDVI e Médio $(0,1<$ $\mathrm{CV}<0,2)$ para o SAVI e EVI.

Durante a atividade de mineração, de 2007 a 2009, a área mostrou uma queda acentuada em seus valores médios, máximos e mínimos, além de um crescimento nos parâmetros de dispersão (Tabela 2). Com a mudança do estágio de desenvolvimento de vegetação densa para solo exposto (Tabela 1), causado pelo desmatamento da área, os valores para os índices reduzem, e consequentemente os parâmetros estatísticos mínimo, máximo e média também. Para o NDVI, a média decaiu em $60,8 \%$, para o SAVI em $59,9 \%$, e para o EVI em $63,8 \%$, ou seja, todos os índices apresentaram impactos equivalentes e representativos. O valor médio das imagens desse período para o índice SAVI está próximo do limite superior da classificação de campo aberto e, para os índices NDVI e EVI, no limite inferior da classificação de vegetação esparsa, assim, mesmo em classes distintas, as condições são parecidas (Tabela 1). Os valores máximo e mínimo dos três índices caíram mais de $40 \%$ em relação à média do período antes da mineração. Estando os máximos dos três índices na faixa de vegetação esparsa e os mínimos na faixa de campo aberto (Tabela 1). O desvio-padrão também cresceu em relação ao 
período antes da mineração, indicando uma maior dispersão de valores para a área, o que pode ser confirmado pelo CV classificado como "Muito Alto" $(\mathrm{CV}>0,3)$.

O período pós-mineração apresentou valores intermediários em relação aos períodos anteriores à atividade. Assim, observa-se que, apenas 10 anos após o início da regeneração, a região está em processo de recuperação, porém, ainda não se encontra em estágio vegetal avançado, como o anterior à mineração. Isso ocorre devido à necessidade de períodos de tempo superiores aos aplicados no artigo, principalmente no que diz respeito à riqueza do bioma Amazônico (Parrotta \& Knowles, 2001).

Os valores médios para os três índices decaíram, e são classificados na faixa de vegetação esparsa (Tabela 1). O estágio pode ser considerado intermediário, porém deve-se levar em conta que são utilizados no cálculo os dados durante todo o período, ou seja, os valores médios são menores que os mais atuais. Com isso, o estágio de desenvolvimento mais recente (2019) é mais desenvolvido do que o médio para o período (20102019). Os valores absolutos máximos aumentaram cerca de 0,200 em relação aos valores do período durante a mineração, classificados na faixa de vegetação densa (Tabela 1). Os valores absolutos mínimos cresceram menos em relação aos valores máximos, cerca de 0,100 , o que reflete o fato de que a área não foi impactada de forma homogênea, mantendo áreas em faixas de vegetação menos desenvolvidas (Tabela 1). Os valores de desvio padrão são os maiores considerando os três períodos, porém, têm um $\mathrm{CV}$ menor, mas ainda classificado como "Muito Alto" $(\mathrm{CV}>0,3)$ para todos os índices, o que demonstra a grande diferença entre os valores, dado que a área está em processo de recuperação devido ao curto período de tempo desde a aplicação da técnica.

A Tabela 3 apresenta os valores dos índices para todos os períodos separados por meses e a média total. Quanto ao período pré-mineração, como a tendência é que os valores não variem de ano para ano, dado a inexistência de fatores externos registrados, os dados foram considerados de forma unitária e separados com relação aos meses de aquisição, onde a média foi calculada e apresentada na Tabela 3. Para os demais períodos, os valores por ano foram apresentados com relação aos meses de aquisição, além da média anual.

Tabela 3. Valores mensais e média anual, no período entre 2007 e 2019, valores mensais médios e média para o período de 1984-2006, para o Índice de Vegetação por Diferença Normalizada (NDVI), Índice de Vegetação Ajustado ao Solo (SAVI) e o Índice de Vegetação Melhorado (EVI). Fonte: Cugula et al. (2021).

\begin{tabular}{ccccccccccc}
\hline Índices & Anos & \multicolumn{1}{c}{ Junho } & Julho & Agosto & Setembro & Outubro & Novembro & Dezembro & Média \\
\hline & $1984-2006$ & 0,834 & 0,831 & 0,780 & 0,807 & 0,751 & 0,770 & 0,698 & 0,805 \\
& 2007 & 0,537 & - & - & 0,453 & - & - & - & 0,495 \\
& 2008 & - & 0,263 & 0,203 & - & - & - & - & 0,243 \\
& 2009 & - & - & 0,243 & - & - & - & - & 0,243 \\
& 2010 & - & 0,325 & - & - & - & 0,299 & 0,298 & 0,307 \\
& 2011 & - & - & - & 0,343 & - & - & - & 0,343 \\
NDVI & 2013 & - & - & - & - & 0,537 & - & - & 0,537 \\
& 2014 & - & - & - & - & - & - & 0,516 & 0,516 \\
& 2015 & - & 0,662 & 0,611 & - & - & - & - & 0,637 \\
& 2016 & - & 0,623 & - & 0,570 & - & - & - & 0,570 \\
& 2017 & - & 0,729 & - & - & - & - & - & 0,729 \\
& 2018 & 0,741 & - & - & - & - & - & - & 0,741 \\
& 2019 & - & - & - & - & - & 0,630 & - & 0,630 \\
\hline \multirow{6}{*}{ SAVI } & $1984-2006$ & 0,489 & 0,497 & 0,450 & 0,451 & 0,390 & 0,377 & 0,351 & 0,458 \\
& 2007 & 0,343 & - & - & 0,298 & - & - & - & 0,321 \\
& 2008 & - & 0,135 & 0,132 & - & - & - & - & 0,134 \\
& 2009 & - & - & 0,123 & - & - & - & - & 0,123 \\
& 2010 & - & 0,218 & - & - & - & 0,202 & 0,196 & 0,205 \\
& 2011 & - & - & - & 0,234 & - & - & - & 0,234
\end{tabular}




\begin{tabular}{|c|c|c|c|c|c|c|c|c|c|}
\hline & 2013 & - & - & - & - & 0,344 & - & - & 0,344 \\
\hline & 2014 & - & - & - & - & - & - & 0,233 & 0,233 \\
\hline & 2015 & - & 0,433 & 0,393 & - & - & - & - & 0,413 \\
\hline & 2016 & - & 0,392 & - & 0,370 & - & - & - & 0,370 \\
\hline & 2017 & - & 0,473 & - & - & - & - & - & 0,473 \\
\hline & 2018 & 0,493 & - & - & - & - & - & - & 0,493 \\
\hline & 2019 & - & - & - & - & - & 0,425 & - & 0,425 \\
\hline \multirow{13}{*}{ EVI } & 1984-2006 & 0,511 & 0,520 & 0,490 & 0,485 & 0,441 & 0,448 & 0,445 & 0,495 \\
\hline & 2007 & 0,353 & - & - & 0,316 & - & - & - & 0,335 \\
\hline & 2008 & - & 0,121 & 0,114 & - & - & - & - & 0,119 \\
\hline & 2009 & - & - & 0,113 & - & - & - & - & 0,113 \\
\hline & 2010 & - & 0,198 & - & - & - & 0,195 & 0,185 & 0,193 \\
\hline & 2011 & - & - & - & 0,220 & - & - & - & 0,220 \\
\hline & 2013 & - & - & - & - & 0,333 & - & - & 0,333 \\
\hline & 2014 & - & - & - & - & - & - & 0,208 & 0,208 \\
\hline & 2015 & - & 0,433 & 0,386 & - & - & - & - & 0,409 \\
\hline & 2016 & - & 0,386 & - & 0,360 & - & - & - & 0,360 \\
\hline & 2017 & - & 0,480 & - & - & - & - & - & 0,480 \\
\hline & 2018 & 0,512 & - & - & - & - & - & - & 0,512 \\
\hline & 2019 & - & - & - & - & - & 0,431 & - & 0,431 \\
\hline
\end{tabular}

As imagens para o período anterior à mineração foram obtidas, em sua maioria, dos meses do período de seca, dado que nos meses de maior pluviosidade, a alta quantidade de nuvens nas imagens inviabilizaram a análise. Além disso, a área era ocupada por uma floresta secundária, onde a vegetação apresentava raízes profundas que compensam os meses de seca devido ao fácil acesso às águas subterrâneas e corpos d'água próximos (Nepstad et al., 1994; Huete et al., 2006). Portanto, os meses de maior desenvolvimento da vegetação são aqueles de maior insolação (junho e julho). Os valores mensais para o período anterior à atividade mineradora representam o padrão a ser alcançado na área em regeneração.

Durante a atividade mineradora é perceptível um decaimento dos valores mensais e anuais em função do avanço da degradação da área. Ao se comparar os valores de agosto de 2009 e a média desse mês para o período anterior à atividade mineradora (1984-2006) percebe-se um decaimento dos valores em 68,9\% (NDVI), 72,7\% (SAVI) e 76,9\% (EVI), respectivamente.

Comparando-se as médias anuais de 2009 e 2019, observa-se um crescimento de $159,3 \%$ para o NDVI, $245,5 \%$ para o SAVI e $281,4 \%$ para o EVI (Tabela 3). Os últimos dois índices apresentam um aumento mais similar entre si além de maior do que o do NDVI, o que pode ser justificado por aplicarem fatores de correção do solo em suas equações, tornando-os menos sensíveis aos efeitos de solo de fundo (Huete et al., 1988; Huete et al., 2002). Com isso, para a situação em questão, o EVI e o SAVI podem ser considerados mais indicados.

Apesar de ser esperado um comportamento crescente dos valores absolutos anuais dos índices após o processo de regeneração natural, este fenômeno não ocorreu, como observado nos anos de 2013, 2015 e 2018 (Tabela 3). Este fato pode ser justificado pela sazonalidade observada nas imagens, que foram obtidas de meses diferentes.

Todos os índices, analisando-se um mesmo mês, apresentaram crescimento dos valores com o passar dos anos (Tabela 3). Comparando-se os índices de novembro de 2010 e de 2019 , observase um acréscimo de $110,7 \%$, para o NDVI, $110,4 \%$ SAVI e de $121,0 \%$ para o EVI. Para a área estar em um estágio avançado de recuperação, o valor do índice precisa ser similar ao encontrado antes do impacto. Contrapondo os valores de novembro de 2019 com a média desse mês antes do impacto (Tabela 3) o NDVI e EVI indicaram que a área ainda não alcançou o estágio avançado de recuperação. O SAVI, por sua vez, indica que a área alcançou estágio avançado de recuperação. No entanto, essa recuperação não pode ser confirmada, dada a indisponibilidade de imagens para os demais meses. Assim, após 9 anos de recuperação 
vegetal, 2 dos 3 índices em avaliação indicam que a área ainda não atingiu estágio avançado de recuperação, o que corrobora com o estudo de Martins (2020), que analisou a mesma região no mesmo período, utilizando o método ecológico. Para que este estágio seja alcançado será necessário um acompanhamento que engloba um período superior a, pelo menos, 13 anos (Salomão, Rosa \& Morais, 2007). Não se pode afirmar sobre a duração da recuperação vegetal até o estágio de desenvolvimento avançado ou recuperação total, visto que a maior parte dos estudos concentra suas análises em períodos inferiores a 10 anos (Martins et al., 2020).

A Figura 3 permite realizar uma análise visual da área, em nível de pixel, apresentando os estágios de desenvolvimento vegetal da área de estudo para os três períodos. Ao se trabalhar com resultados numéricos, a região toda é classificada dentro de uma faixa de valores, dando uma falsa impressão de homogeneidade na área. A análise visual, por sua vez, permite observar que a região não se desenvolveu de forma homogênea. As imagens A, D e G da Figura 3, referentes a 2006, classificam a área de estudo, majoritariamente, como vegetação densa para todos os índices, o que é confirmado pelos resultados numéricos. As imagens B, E e H da Figura 3, referentes a 2009, apresentam a maior parte da área classificada como campo aberto, o mesmo indicado pela média numérica deste ano (Tabela 3). Apesar disso, é possível observar outros estágios vegetacionais, como solo exposto e vegetação em estado de transição na fronteira da área de floresta densa. Nas imagens C, F e I da Figura 3, referentes a 2019, existe uma zona mais desenvolvida à direita, classificada como vegetação densa, passando pelas fases de transição e vegetação esparsa até chegar à área de campo aberto, localizada na área mais impactada. Apesar da área, em sua maioria, estar classificada como vegetação densa, as áreas classificadas em outras faixas de vegetação justificam a média geral numérica (Tabela 3 ) na faixa de valores de vegetação de transição.
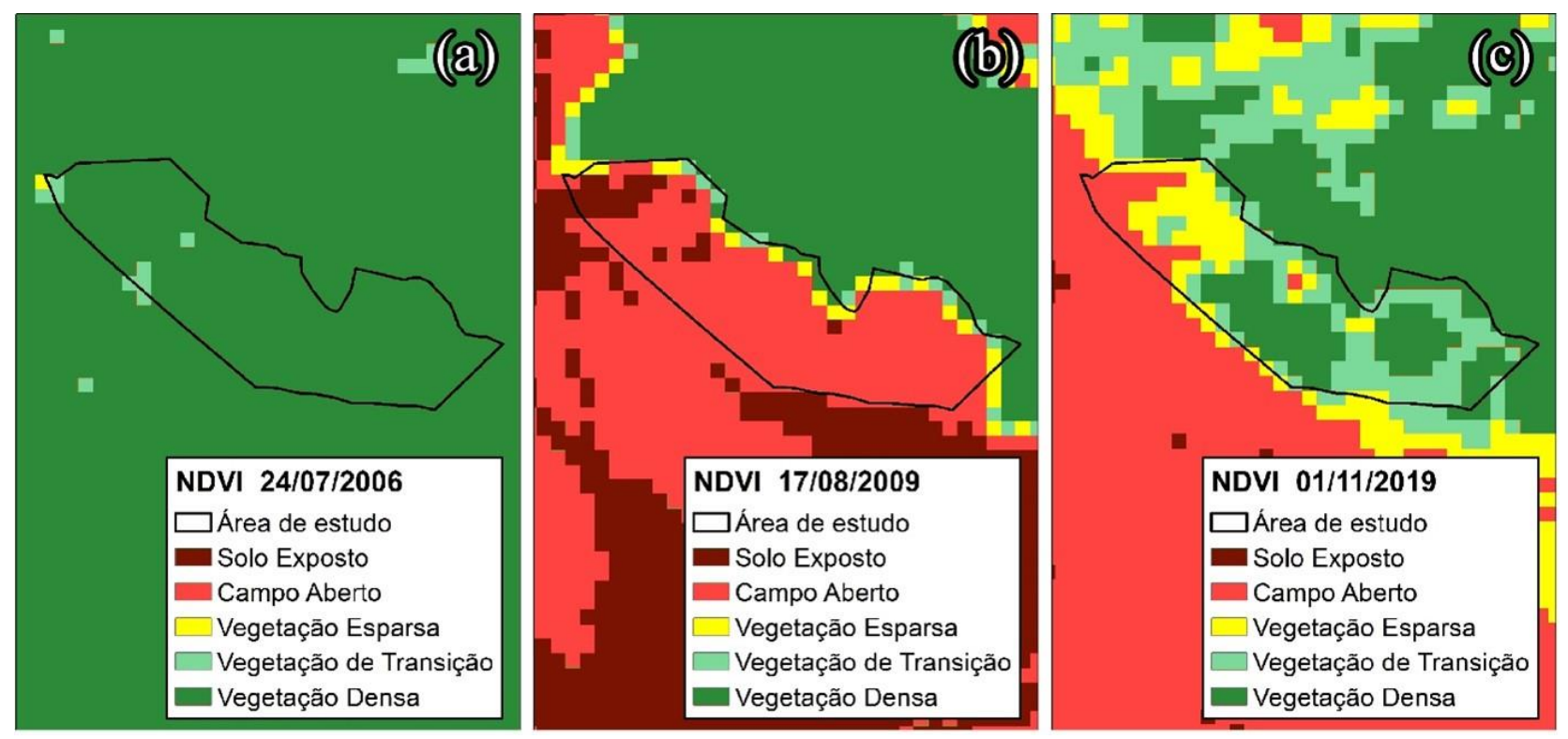

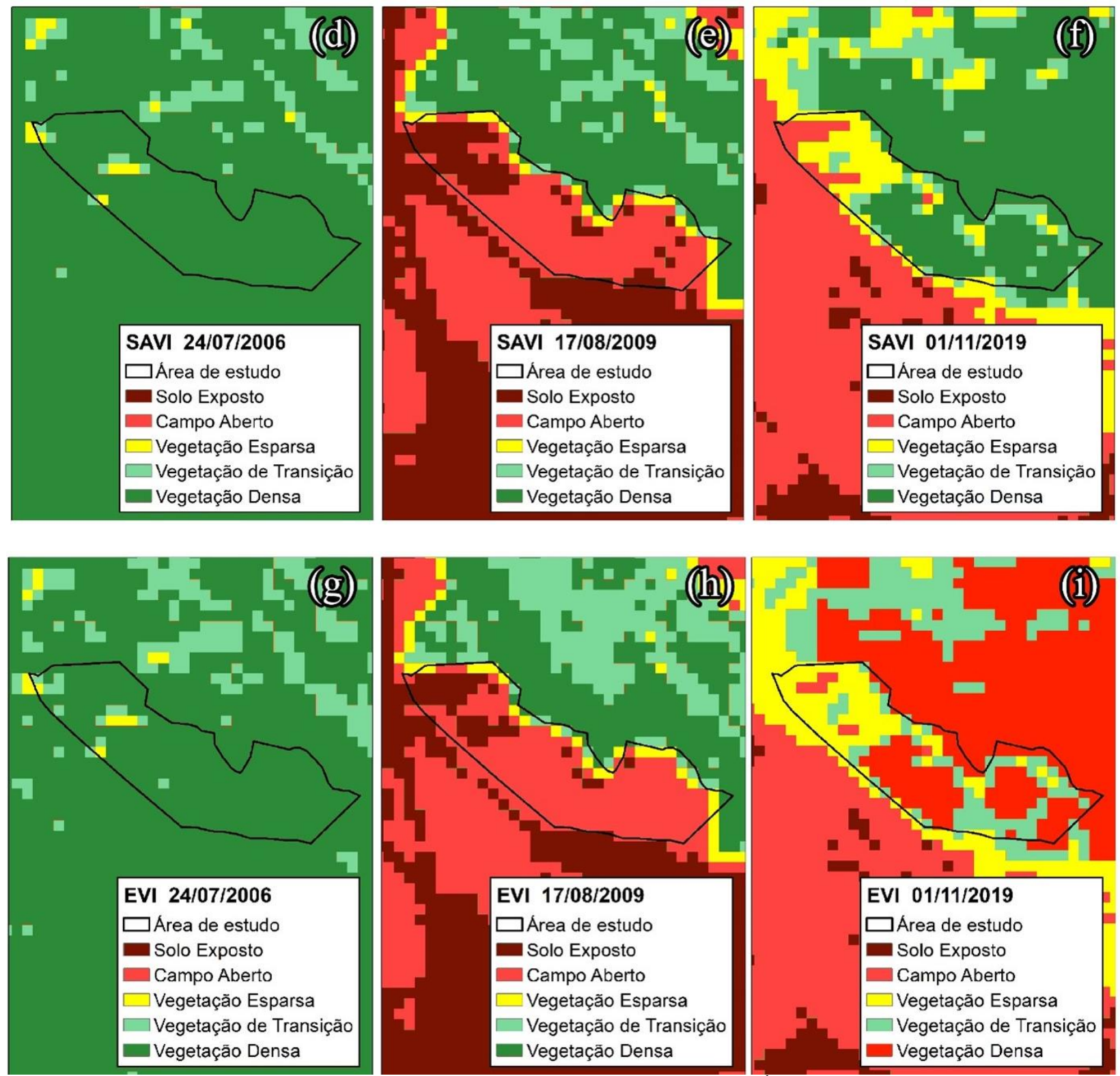

Figura 3. Classificação por estágio de desenvolvimento vegetal para o Índice de Vegetação por Diferença Normalizada (NDVI), Índice de Vegetação Ajustado ao Solo (SAVI) e o Índice de Vegetação Melhorado (EVI), considerando os períodos antes (adg), durante (beh) e depois (cfi) da atividade mineradora. Fonte: Cugula et al. (2021).

A Figura 4 apresenta a análise individual dos valores absolutos de pixels da imagem de 2019 para os três índices de vegetação: NDVI (Figura 4A), SAVI (Figura 4B) e SAVI (Figura 4C). Estas foram classificadas usando faixas de 0,05 de comprimento. Assim, percebe-se que áreas de mesmo estágio sucessional (Figuras 3CFI), podem apresentar intervalos de valores diferentes para $\mathrm{O}$ mesmo estágio de desenvolvimento vegetal. A Figura 4A-C possui distribuições similares de desenvolvimento de vegetação. Em relação às áreas de vegetação densa no ano de 2019 (Figura 3), ao observá-las na Figura 4, percebe-se a presença de dois núcleos mais desenvolvidos, com valores entre 0,70-0,75 (NDVI), 0,50-0,60 (SAVI e EVI), que por serem zonas fechadas longe das estradas conseguiram maior desenvolvimento da vegetação. Ao redor dos núcleos, há zonas de alto desenvolvimento, mas inferiores às dos núcleos. As regiões com os menores valores dos índices e, consequentemente, em estágio de desenvolvimento vegetal inferior, encontram-se no extremo esquerdo das figuras. Dessa forma, o estudo requer mais tempo para que as áreas menos desenvolvidas alcancem valores maiores, atingindo um estágio de desenvolvimento similar ao do período anterior à atividade mineradora, com um resultado mais homogêneo entre os núcleos e seu entorno. 

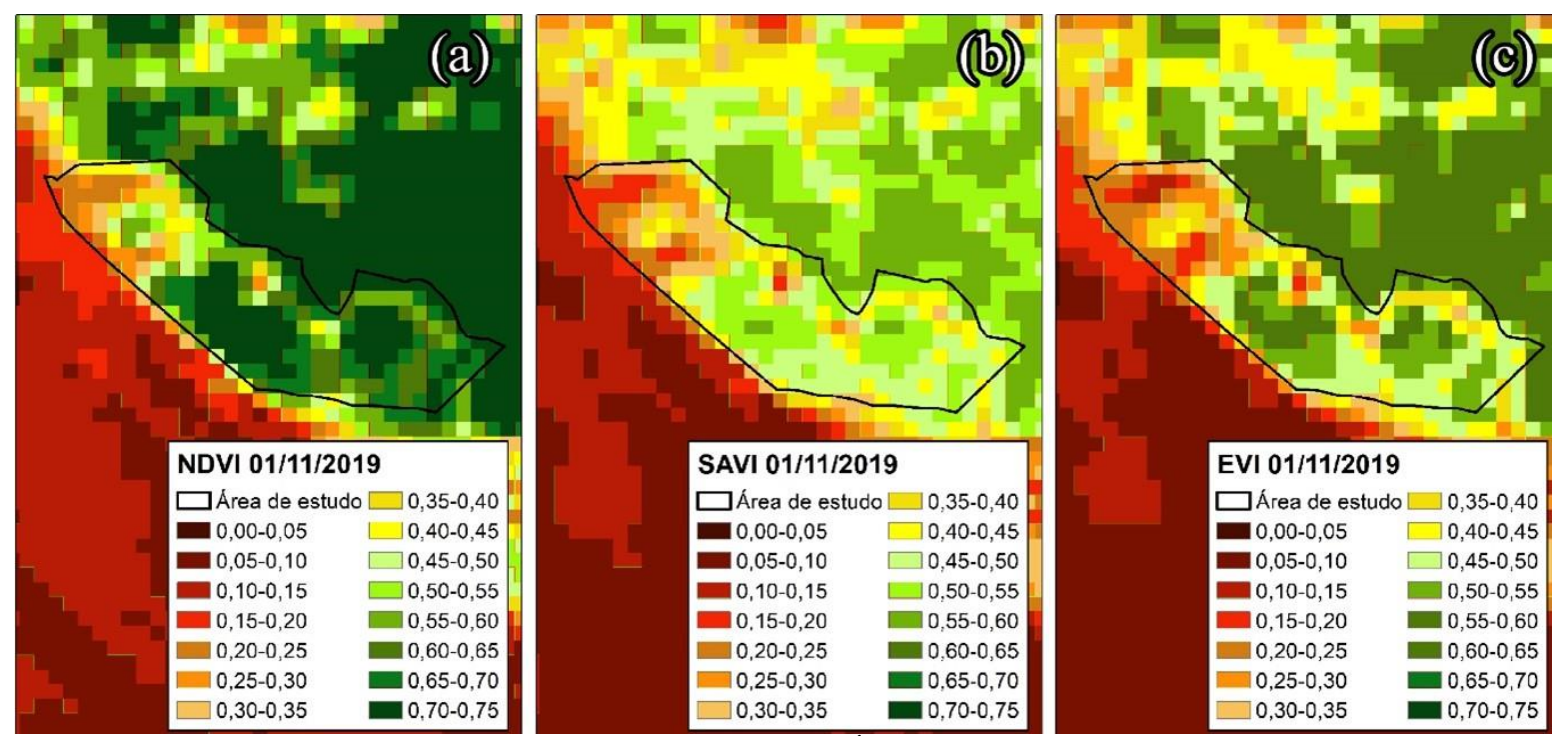

Figura 4. Faixas de valores de índices de vegetação. a. Índice de Vegetação por Diferença Normalizada (NDVI), b. Índice de Vegetação Ajustado ao Solo (SAVI) e c. Índice de Vegetação Melhorado (EVI) para a imagem mais recente do período de estudo. Fonte: Cugula et al. (2021).

Além da análise dos índices de vegetação, existe a possibilidade de análise da recuperação por meio de inspeções locais, a qual pode reiterar os resultados encontrados, como foi feito por Silva et al. (2021). A Figura 5 apresenta registros fotográficos em nível de solo da área interna e externa em análise, respectivamente, obtidos por meio de uma visita técnica à mineradora em 2018.
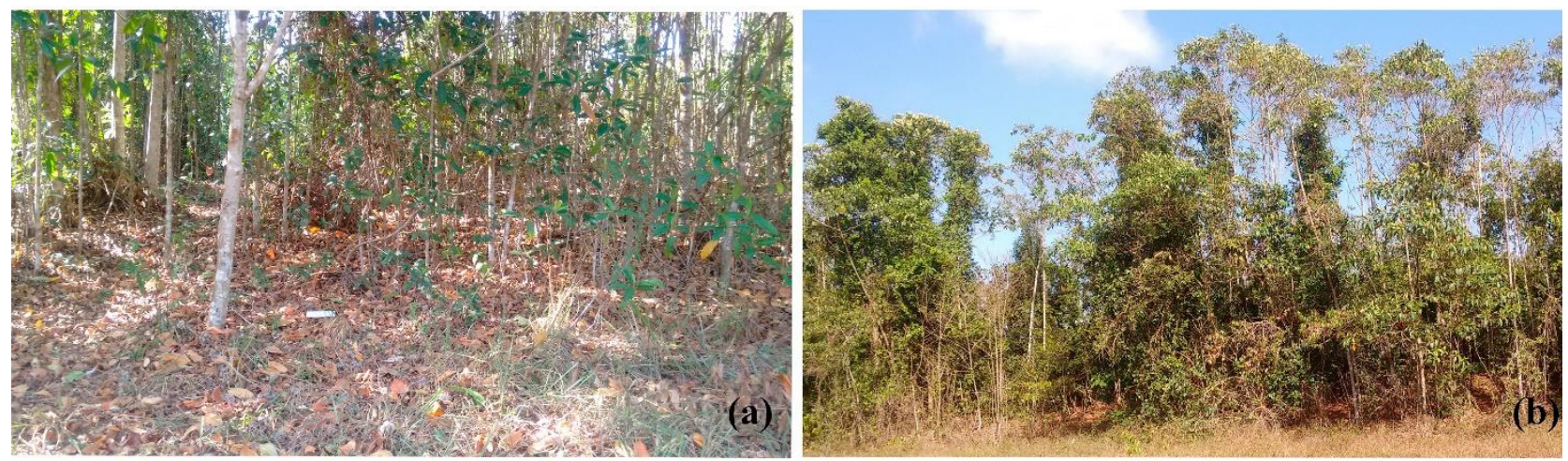

Figura 5. Fotografias das regiões interna (a) e externa (b) da área de estudo, no município de Paragominas-PA, em setembro de 2018. Fonte: Cugula et al. (2021).

Comparando-se a técnica de regeneração natural com a técnica de plantio tradicional, ambas realizadas em 2009, percebe-se que a área de estudo apresentou estado de recuperação mais avançado. Ao contrário do plantio tradicional, que apresenta um espaço definido entre as árvores com aparência de floresta artificial, as áreas de regeneração natural apresentam uma floresta mais densa. Na região, as árvores mais desenvolvidas apresentavam duas faixas de altura principais, sendo as mais altas de $20 \mathrm{~m}$ a $25 \mathrm{~m}$ e as demais entre $10 \mathrm{~m}$ e $15 \mathrm{~m}$. Também, notou-se que a área apresentava uma variedade de estágios de sucessão, representando que se encontrava no início do alcance de um estágio avançado, resultado similar ao apresentado pelos valores numéricos dos índices de vegetação utilizados (Figura 4). A serapilheira estava estabelecida, o que significa que, em menos de 10 anos após a aplicação da técnica de regeneração natural, havia a presença de uma camada orgânica do solo estabelecida.

\section{Conclusão}

O período de análise de 36 anos (1984 a 2019) foi suficiente para obter uma quantidade confiável de imagens para o período de prémineração (até 2006), além de quantificar o impacto causado pela atividade (até 2009) e monitorar o avanço da recuperação vegetal, que em 2019 se encontrava em fase intermediária. No geral, a técnica de regeneração natural, mostrou-se eficiente para a melhoria da área com base nos resultados das análises numéricas e visuais realizadas. 
No que diz respeito à análise numérica, percebeu-se o crescimento dos valores dos índices de vegetação durante o período de recuperação. No entanto, o estágio avançado de recuperação foi alcançado somente com o índice SAVI, apesar de não haver dados suficientes para a confirmação desta recuperação. Com isso, verifica-se que após 10 anos da aplicação da técnica, a região ainda não atingiu estágio avançado de recuperação, requerendo maior tempo de análise $\mathrm{e}$ monitoramento da área. Conforme resultados crescentes dos índices, percebe-se que em um intervalo curto de tempo tal estágio poderá ser alcançado. A longo prazo, mantendo esse comportamento, a área poderá ser classificada, em sua maioria, como vegetação densa.

Os índices de vegetação permitiram o monitoramento da dinâmica vegetal. A utilização de três índices elevou o grau de confiabilidade dos resultados, bem como possibilitou a comparação da sensibilidade entre eles. Os fatores de correção, para amenizar os efeitos do solo do SAVI e EVI, foram essenciais para o resultado favorável em relação ao NDVI. Por isso, embora seja um dos índices de vegetação mais utilizados, o NDVI não se mostrou adequado para este estudo e consequentemente não se indica para pesquisas similares posteriores.

A avaliação visual detectou a heterogeneidade da área quanto à recuperação, o que possibilita a definição de regiões passíveis de futuras intervenções com o intuito de maximizar o potencial de recuperação. Considerando os estágios de desenvolvimento vegetal, para o ano de 2019, o valor médio a classificaria como em estágio transicional, porém visualmente identificase estágios que variam de campo aberto até vegetação densa, com predominância desta última.

$\mathrm{O}$ estudo permitiu monitorar $\mathrm{o}$ avanço da recuperação vegetal, porém, a recuperação de um ecossistema é dependente de diversos fatores bióticos e abióticos. Um sistema vegetal recuperado e estabelecido no bioma amazônico prevê uma rica biodiversidade, e para que isso seja alcançado, as técnicas de recuperação precisam ser estrategicamente escolhidas e acompanhadas a longo prazo.

\section{Agradecimentos}

Os autores agradecem à Mineração Paragominas S. A. pelo fornecimento dos dados necessários para a realização da pesquisa e receber a equipe da Universidade Federal do Rio de Janeiro durante a visita à Empresa. $\mathrm{O}$ estudo foi realizado com apoio da Coordenação de Aperfeiçoamento de Pessoal de Nível Superior - Brasil (CAPES) Código de Financiamento 001. Esteves, E.M.M. agradece a bolsa de estudos da Agência Nacional do Petróleo, Gás Natural e Biocombustíveis (PRH 17.1 / ANP-Finep).

\section{Referências}

ABAL - Associação Brasileira do Alumínio. 2017. Bauxita no Brasil: Mineração Responsável e Competitividade. Disponível em: http://abal.org.br/downloads/publicacoes/bau xita-no-Brasil-mineracao-responsavel-ecompetitividade-eng.pdf. Acesso em: 2 março 2020.

Almeida, R. O. P. O. 2002. Revegetação de áreas mineradas: Estudo dos procedimentos aplicados em minerações de areia. Tese de Mestrado, Universidade de São Paulo, São Paulo, São Paulo, Brasil. 160p.

Alves, C. N.; Ferreira, N. L.; Souza, G. B.; Barroso, L. L.; Silva, J. A. F.; Brito, R. B. M.; Melo, E. E. P. 2021. Caracterização de atributos físicoquímicos de um latossolo amarelo no Município de Paragominas-PA. Research, Society and Development., 10, 2, e10010212130. https://doi.org/10.33448/rsdv10i2.12130

ANM - Agência Nacional de Mineração. 2020. Mineração. Disponível em: <www.dnpmpe.gov.br/Geologia/Mineracao.php>. Acesso em: 2 de março de 2020.

Araújo, R. A.; Silva, J. L. S.; Cugula, J. S.; Paschoal, J. P.; Esteves, V. P. P.; Morgado, C. R. V. 2020. Assessment of vegetation recomposition methods in a tropical forest using satellite images. Clean Technologies and Environmental Policy, 23, (3), 1-14. https://doi.org/10.1007/s10098-020-01916-w

Bacalhau, J. R.; Ribeiro Neto, A.; Oliveira, L. M. M. 2017. Aplicação de índice de vegetação no monitoramento da seca: açude Algodões no sertão pernambucano. Journal of Environmental Analysis and Progress. 2, 283293.

https://doi.org/10.24221/jeap.2.3.2017.1449.

Boratto, I. M.; Gomide, R. L. 2013. Aplicação dos índices de vegetação NDVI, SAVI e IAF na caracterização da cobertura vegetativa da região Norte de Minas Gerais. Anais XVI Simpósio Brasileiro de Sensoriamento Remoto, Foz do Iguaçu, PR, Brasil, INPE.

Brasil. 2012. Presidência da República Casa Civil Subchefia para Assuntos Jurídicos. Lei $\mathrm{N}^{\circ}$ 12.651, de 25 de maio de 2012. Disponível em:

<http://www.planalto.gov.br/ccivil_03/_ato2 011-2014/2012/lei/112651 compilado.htm>. Acesso em: 10 de maio de 2020. 
Bunker, S. G. 1985. Under developing the Amazon. Chicago: University of Chicago Press.

Carvalho, S. P.; Costa, M. C.; Oliveira, M. D. C. F. 2005. Comportamento da precipitação pluviométrica no município de ParagominasPA. Anais XIV Congresso Brasileiro de Agrometeorologia, Campinas, SP, Brasil, SBAgro.

Chagas, M. das G. S. das.; Galvíncio, J. D.; Pimentel, R. M. de M. 2008. Avaliação da dinâmica espectral da vegetação de Caatinga em Arcoverde, Pernambuco. Revista de Geografia, 25, (2), 45-60.

Departamento Nacional de Produção Mineral (DNPM). 2017. Anuário Mineral Brasileiro: Principais Substâncias Metálicas. Disponível em:

http://www.anm.gov.br/dnpm/publicacoes/se rie-estatisticas-e-economia-mineral/anuariomineral/anuario-mineral-

brasileiro/amb_metalicos2017. Acesso em: 25 de fevereiro de 2019.

Departamento Nacional de Produção Mineral (DNPM) 2018. Anuário Mineral Brasileiro: Principais Substâncias Metálicas. Disponível em:

http://www.anm.gov.br/dnpm/publicacoes/se rie-estatisticas-e-economia-mineral/anuariomineral/anuario-mineral-

brasileiro/amb_2018.pdf. Acesso em: 1 de março 2019.

Duarte, M. L.; Brito, W. B. M.; Silva, T. A.; Castro, A. L. 2020. Padrões e causas do desmatamento no Baixo Acre, região oeste da Amazônia brasileira. Journal of Environmental Analysis and Progress, 5, (1), 117-127. https://doi.org/10.24221/jeap.5.1.2020.2790.

Eastman, J. R. 2006. Idrisi Andes - Guide to GIS and Image Processing. Clark university, Worcester. 284p.

Esteves, V. P. P.; Esteves, E. M. M.; Bungenstab, D. J.; Loebmann, D. G. D. S. W.; Victoria, D. C.; Vicente, L. E.; Araújo, O. D. Q. F.; Morgado, C. D. R. V. 2016. Land use change (LUC) analysis and life cycle assessment (LCA) of Brazilian soybean biodiesel. Clean Technologies and Environmental Policy, 18, (6), 1655-1673. https://doi.org/10.1007/s10098-016-1161-8

Francez, L. M. D. B.; Carvalho, J. O. P. D.; Jardim, F. C. D. S.; Quanz, B.; Pinheiro, K. A. O. 2009. Efeito de duas intensidades de colheita de madeira na estrutura de uma floresta natural na região de Paragominas, Pará. Acta Amazonica, 39, (4), $851 \quad$ - 864.
http://dx.doi.org/10.1590/S0044-

59672009000400014

Gao, X.; Huete, A. R.; Ni, W.; Miura, T. 2000.

Optical-biophysical relationships of vegetation spectra without background contamination. Remote sensing of environment, 74, (3), 609-620. https://doi.org/10.1016/S00344257(00)00150-4

Gilabert, M. A.; González-Piqueras, J.; GarcíaHaro, F. J.; Melia, J. 2002. A generalized soiladjusted vegetation índex. Remote Sensing of Environment, 82, (2-3), 303-310. https://doi.org/10.1016/S00344257(02)00048-2

Gomes, F. P. 1985. Curso de estatística experimental. São Paulo: Nobel, $10^{a}$ Edição. $467 \mathrm{p}$.

Huete, A. R. 1988. A soil-adjusted vegetation index (SAVI). Remote Sensing of Environment, 25, (3), 295-309. https://doi.org/10.1016/00344257(88)90106-X

Huete, A.; Didan, K.; Miura, T.; Rodriguez, E. P.; Gao, X.; Ferreira, L. G. 2002. Overview of the radiometric and biophysical performance of the MODIS vegetation indices. Remote Sensing of Environment, 83, (1-2), 195-213. https://doi.org/10.1016/S00344257(02)00096-2

Huete, A.; Justice, C.; Van Leeuwen, W. 1999. MODIS vegetation index (MOD13). Algorithm theoretical basis document.Version 3 (213).

Huete, A. R.; Didan, K.; Shimabukuro, Y. E.; Ratana, P.; Saleska, S. R.; Hutyra, L. R.; Yang, W.; Nemani, R. R.; Myneni, R., 2006. Amazon rainforests green-up with sunlight in dry season. Geophysical Research Letters, 33, L06405. https://doi.org/10.1029/2005GL025583

IBRAM - Instituto Brasileiro de Mineração. 2018. Relatório Anual de Atividades Julho de 2017 - Junho de 2018. Disponível em: http://portaldamineracao.com.br/ibram/wpcontent/uploads/2019/07/relatorio-anaul2018-2019.pdf. Acesso em: 23 de abril de 2020.

Jesus, E. N. D.; Santos, T. S. D.; Ribeiro, G. T.; Orge, M. D. R.; Amorim, V. O.; Batista, R. C. R. C. 2016. Natural Regeneration of Plant Species in Revegetated Mining Areas. Floresta e Ambiente, 23, (2), 191-200. https://doi.org/10.1590/2179-8087.115914

Konecny, G. 2014. Geoinformation: remote sensing, photogrammetry and geographic 
information systems. CRC Press, Second Edition.

Laurentino, M. L. S.; Silva, H. A.; Silva, J. C. B.; Santana, S. H. C.; Morais, Y. C. B.; Galvíncio, J. D. 2011. Aplicação dos índices de NDVI e EVI como análise da variação fisionômica da vegetação no Brejo de Altitude de Serra Negra-Bezerros/PE-Brasil. Anais XV Simpósio Brasileiro de Sensoriamento Remoto R, Curitiba, PR, Brasil, INPE.

Ma, B.; Pu, R.; Wu, L.; Zhang, S. 2017. Vegetation index differencing for estimating foliar dust in an ultra-low-grade magnetite mining area using landsat imagery. Ieee Access, 5, 88258834 .

https://doi.org/10.1109/ACCESS.2017.2700 474

Marcuzzo, S. B.; Ganade, G.; Araújo, M. M.; Muniz, M. F. B. 2013. Comparação da eficácia de técnicas de nucleação para restauração de área degradada no sul do Brasil. Floresta, 43, (1), 39-48. https://doi.org/10.5380/rf.v43i1.28680

Mariath, J. E. A.; Santos, R. P. 2006. Os avanços da Botânica no início do Século XXI. Sociedade Botânica do Brasil, Porto Alegre.

Martins, W. B. R. 2020. Restauração de ecossistemas degradados pela mineração na Amazônia Oriental. Tese de Doutorado, Universidade Federal Rural da Amazônia, Belém, Pará, Brasil. 140p.

Martins, W. B. R.; Ferreira, G. C.; Oliveira, F. A. 2018. Deposição de serapilheira e nutrientes em áreas de mineração submetidas a métodos de restauração florestal em Paragominas, Pará. Floresta, 48, (1), 37-48. https://doi.org/10.5380/rf.v48i1.49288

Martins, W. B. R.; Lima, M. D. R.; Barros Junior, U. D. O. B.; Amorim, L. S. V. B.; Oliveira, F. A.; Schwartz, G. 2020. Ecological methods and indicators for recovering and monitoring ecosystems after mining: A global literature review. Ecological Engineering, 145, 105707. https://doi.org/10.1016/j.ecoleng.2019.10570 7

Ministério da Economia. 2020. Balança comercial brasileira. Disponível em: http://www.mdic.gov.br/index.php/comercio -exterior/estatisticas-de-comercioexterior/base-de-dados-do-comercioexterior-brasileiro-arquivos-para-download. Acesso em: 24 de abril de 2020.

Ministério da Economia. 2020. Exportação brasileira - Dados até Março de 2020. Disponível em: http://www.mdic.gov.br/index.php/comercio -exterior/estatisticas-de-comercioexterior/base-de-dados-do-comercioexterior-brasileiro-arquivos-para-download>. Acesso em: 24 de abril de 2020.

Montgomery, D. C.; Runger, G. C. 2010. Applied statistics and probability for engineers. John Wiley \& Sons, Quinta Edição. 784p.

Nepstad, D. C.; Carvalho, C. R.; Davidson, E. A.; Jipp, P. H.; Lefebvre, P. A.; Negreiros, G. H.; Silva, E. D.; Stone, T. A.; Trumbore, S. E.; Vieira, S. 1994. The role of deep roots in the hydrological and carbon cycles of Amazonian forests and pastures. Nature, 372, (6507), 666-669. https://doi.org/10.1038/372666a0

Oliveira, I. M. S.; Sales, A. D.; Silveira, E. M. O.; Acerbi Júnior, F. W.; Mello, J. M. 2017. Análise multitemporal da regeneração natural da candeia após ocorrência de incêndio florestal. Revista Verde de Agroecologia e Desenvolvimento Sustentável, 12, (2), 192197.

https://doi.org/10.18378/rvads.v12i2.4719

Parrotta, J. A.; Knowles, O. H. 2001. Restoring tropical forests on lands mined for bauxite: examples from the Brazilian Amazon. Ecological Engineering, 17, (2-3), 219-239. https://doi.org/10.1016/S09258574(00)00141-5.

Pereira, I. C. B.; Souza, L. S. F. 2019. Fertilidade do solo construído em áreas degradadas sob recuperação após mineração de Bauxita em Paragominas-PA. Monografia, Universidade Federal Rural da Amazônia, Belém, Pará, Brasil. 41p.

Pinheiro, J.; Cunha, S.; Gomes, G.; Carvajal, S. 2012. Probabilidade e estatística: quantificando a incerteza. Elsevier Brasil. GEN LTC, Primeira Edição.

Qi, X.; Wang, K.; Zhang, C. 2013. Effectiveness of ecological restoration projects in a karst region of southwest China assessed using vegetation succession mapping. Ecological Engineering, 54, 245-253. https://doi.org/10.1016/j.ecoleng.2013.01.00 2

Reis, A.; Bechara, F. C.; Espíndola, M. D.; Vieira, N. K.; Souza, L. D. 2003. Restauração de áreas degradadas: a nucleação como base para incrementar os processos sucessionais. Natureza \& Conservação, 1, (1), 28-36.

Rodrigues, T. E.; Silva, R. D. C.; Silva, J. M. L.; Oliveira Junior, R. C.; Gama, J. R. N. F.; Valente, M. A. 2003. Caracterização e classificação dos solos do município de Paragominas, Estado do Pará. Embrapa Amazônia Oriental-Documentos (INFOTECA-E), Belém, Pará, Brasil. 
Rouse, J. W.; Haas, R. H.; Schell, J. A; Deering, D. W. 1974. Monitoring vegetation systems in the great plains with ERTS, Proceedings, Thrid Earth Resources. Technology Satellite1 Symposium, Greenbelt: NASA, 351, (1974), 309-317.

Salomão, R. P.; Rosa, N. A.; Morais, K. A. C. 2007. Dinâmica da regeneração natural de árvores em áreas mineradas na Amazônia. Boletim do Museu Paraense Emílio Goeldi Ciências Naturais, Belém, 2, (2), 85-139.

Sampaio, J. A.; Andrade, M. C.; Dutra, A. J. B. Bauxita. In: Rochas \& minerais industriais: usos e especificações. Rio de Janeiro: CETEM, 2005. Parte II. Cap.13, pp. 279-304.

Schorn, L. A.; Krieger, A.; Nadolny, M. C.; Fenilli, T. A. B. 2010. Avaliação de técnicas para indução da regeneração natural em área de preservação permanente sob uso anterior do solo com Pinus elliottii. Floresta, 40, (2), 281294.

http://dx.doi.org/10.5380/rf.v40i2.17824

Shank, M. 2008. Using remote sensing to map vegetation density on a reclaimed surface mine. Proceedings of "Incorporating Geospatial Technologies into SMCRA Business Processes", Atlanta, GA, USA. 20p.

Silva, J. L. de S.; Araujo, R. A.; Esteves, V. P. P.; Loebmann, D. G. S. W.; Vicente, L. E.; Paschoal, J. P.; Morgado, C. R. V. 2021. Analysis of vegetation recovery in areas impacted by bauxite mining in the Amazon Forest. Clean Technologies Environmental Policy, 23, (3), 797-810. https://doi.org/10.1007/s10098-021-02052-9

Silva, K. A.; Martins, S. V.; Miranda Neto, A.; Demolinari, R. A.; Lopes, A. T. 2016. Restauração florestal de uma mina de bauxita: avaliação do desenvolvimento das espécies arbóreas plantadas. Floresta e Ambiente, 23, (3), 309-319. https://doi.org/10.1590/21798087.142515

Sirtoli, A. E. 1998. Detecção da expansão de área de mineração através de técnicas de sensoriamento remoto. Dissertação de Mestrado, Universidade Federal do Paraná. Curitiba, Paraná, Brasil. 111p.

Soares, A. A. V. 2012. Modelos de Implantação de Matas Ciliares em Margem de Reservatório. Tese de Mestrado, Universidade Federal de Lavras, Lavras, Minas Gerais, Brasil. 84p.

Sousa, L. M.; Adami, M.; Lima, A. M. M.; Ramos, W. F. 2017. Avaliação do uso e cobertura da terra em Paragominas e Ulianópolis-PA, utilizando dados do projeto TerraClass.
Revista Brasileira de Cartografia, 69, (3), 421-431.

Thompson, K. N. N.; Lima, W. A. S. 2017. Dinâmica do uso da terra no município de Paragominas-PA. Monografia, Universidade Federal Rural da Amazônia, Paragominas, Pará, Brasil. 36p.

Trindade, J. R. B. 2019. Empresas Transnacionais, Territorialidade e Impactos Ambientais na Região Amazônica Oriental Brasileira. Celia Regina Congilio, Rosemayre Bezerra, pp. 1548.

U.S. Geological Survey (USGS). 2019. Mineral commodity summaries 2019: U.S. Geological Survey. https://doi.org/10.3133/70202434

200p.

U.S. Geological Survey (USGS). 2020. Landsat Missions. Disponível em:

<https://www.usgs.gov/landresources/nli/landsat/landsat-satellitemissions?qtscience_support_page_related_con=2\#qtscience_support_page_related_con>. Acesso em: 1 de abril de 2020.

Wanderley, L. J. D. M. 2008. Conflitos e movimentos sociais populares em área de mineração na Amazônia brasileira. Dissertação de Mestrado, Universidade Federal do Rio de Janeiro, Rio de Janeiro, Rio de Janeiro, Brasil. 163p.

Wilson, N. R.; Norman, L. M. 2018. Analysis of vegetation recovery surrounding a restored wetland using the normalized difference infrared index (NDII) and normalized difference vegetation index (NDVI). International Journal of Remote Sensing, 39, (10), 3243-3274. https://doi.org/10.1080/01431161.2018.1437 297

Worlanyo, A. S.; Jiangfeng, L. 2021. Evaluating the environmental and economic impact of mining for post-mined land restoration and land-use: A review. Journal of Environmental Management, 279, 111623. https://doi.org/10.1016/j.jenvman.2020.1116 23

Xu, P.; Zhou, T.; Zhao, X.; Luo, H.; Gao, S.; Li, Z.; Cao, L. 2018. Diverse responses of different structured forest to drought in Southwest China through remotely sensed data. International Journal of Applied Earth Observation and Geoinformation, 69, 217225. https://doi.org/10.1016/j.jag.2018.03.009 